\title{
A jurisprudência rotal como serviço à Igreja e à humanidade nas alocuções de João Paulo II
}

\author{
The rotal jurisprudence as a service to the Church \\ and humanity in the speeches of John Paul II
}

\section{Denilson Geraldo ${ }^{1}$}

Resumo: $\mathrm{O}$ artigo reúne as 26 alocuções de João Paulo II ao Tribunal da Rota Romana e apresenta o direito com uma origem e finalidade teológica, superando o conceito de ius como mera organização eclesial, mas exigindo a observância das leis para salvaguardar o direito de defesa das pessoas e do sacramento do matrimônio. Os discursos tratam também da pastoralidade do direito e sua eficácia na vida eclesial, oferecendo uma hermenêutica jurídica canônica com fidelidade à lei e em vista da salvação.

Palavras-chaves:

Tribunal da Rota Romana, Teologia do Direito, Pastoralidade do Direito.
Abstract: The article brings together the 26 speeches of John Paul II to the Tribunal of the Roman Rota and presents the law with a theological origin and purpose, surpassing the concept of ius as mere ecclesial organization, but requiring the observance of the laws to safeguard the right to defend people and the sacrament of matrimony. The discourses also deal with the pastorality of law and its efficacy in the ecclesial life, offering a canonical legal hermeneutics with fidelity to the law and in view of salvation.

\section{Keywords:}

The Roman Rota Tribunal, Theology of Law, Pastorality of Law.

\section{Introdução}

As alocuções do Papa João Paulo II ao Tribunal Apostólico da Rota Romana demonstram a função judicial da Igreja Católica a serviço da equidade, da caridade e dos direitos humanos, fazendo um encontro entre a legislação canônica e os direitos da pessoa, impelindo

\footnotetext{
Doutor em Direito Canônico pela Pontifícia Universidade Lateranense de Roma; Professor do Instituto Superior de Direito Canônico de Santa Catarina e do Instituto de Direito Canônico de Londrina. Diretor do Istituto San Vincenzo Pallotti (Roma). Email: denil.ge@gmail.com
} 
os membros dos tribunais eclesiásticos a serem sacerdotes da justiça como função pastoral voltada para a comunhão.

Os discursos estão na perspectiva de levar os agentes do poder judiciário canônico a procurar pela verdade, suprema norma da justiça, com fundamento bíblico e teológico, mantendo a fidelidade ao conceito de matrimônio oriundo da Revelação e inerente à natureza humana, mesmo diante de uma cultura relativista. A família constitui o fundamento para a sociedade e a ação jurisprudencial da Rota consiste em reconhecer e respeitar o pleno valor do matrimônio firmado no consentimento matrimonial que é também um ato eclesial.

João Paulo II mencionou diversas vezes, em seus discursos, que o novo Código de Direito Canônico por ele promulgado em 1983 possibilitou proteger a liberdade das pessoas e o desenvolvimento dos carismas e da caridade, tornando ágeis os trâmites dos processos, mas sem detrimento da própria justiça. Ressaltou, diversas vezes, que o novo Código está em consonância com o Vaticano II e exigiu que os agentes do judiciário canônico conhecessem o factum e o ius e considerassem a mens legislatoris e a ratio legis; a fidelidade às normas jurídicas e a jurisprudência do direito matrimonial.

Os temas também discorrem sobre o direito de defesa que exige a observância do direito processual, resultando em verdadeiro valor pastoral a aplicação das leis canônicas como adequadas ao bem das pessoas. Repropor pela jurisprudência rotal a integralidade da mensagem evangélica sobre o matrimônio é salvaguardar a perenidade da lei divina e a estabilidade da norma canônica e, simultaneamente, tutelar e defender a dignidade do homem.

Além da missão antropológica, o Tribunal da Rota Romana participa do ministério petrino; sua jurisprudência é imprescindível aos tribunais diocesanos e objeto de estudo para as faculdades de direito canônico. Esta é uma missão, fundamentalmente, evangélica, eclesial e sacerdotal. É um serviço a Deus e aos homens como um ato de caridade, pois Deus é amor e o homem participa da vida de Deus no matrimônio sacramento, sinal do amor do Cristo pela Igreja. 


\section{O novo código e seus efeitos na jurisprudência rotal}

Em 1983, a poucos dias da promulgação do Novo Código de Direito Canônico, João Paulo II afirmou que a jurisprudência rotal exerceu importante função na transição entre o antigo e o novo código e tutelou os conteúdos essenciais do matrimônio. Nesse discurso, o Pontífice discorre sobre a nova legislação que "deverá oferecer um claro roteiro e um válido auxílio para viver corajosamente as verdades evangélicas e a própria vocação na Igreja de Cristo". O ministério do juiz eclesiástico é, por isso, o de intérprete da justiça e do direito dos fiéis que reconhecerão os deveres de unidade e solidariedade na Igreja como corresponsabilidade de todos na construção da própria Igreja, exigindo o respeito das atribuições de cada um, segundo o próprio estatuto jurídico como garantia das liberdades individuais. A lei canônica, "atribuindo a primazia ao amor, à graça e aos carismas, torna ao mesmo tempo mais fácil o seu orgânico desenvolvimento na vida, quer da sociedade eclesial quer também de cada um dos membros da Igreja”. Quanto à função do juiz e à atividade judiciária na Igreja, é preciso pôr em relevo sua liberdade decisória com idoneidade, competência e rapidez processual, sem detrimento da justiça, e salvaguardando os direitos de todos ${ }^{2}$.

O Pontífice afirmou em 1984 que o novo Código de Direito Canônico foi "fruto de longo trabalho, paciente e esmerado, enriquecido por diversas consultas do Episcopado que lhe imprimiram uma nota particular de colegialidade". Na verdade, este código representa um guia autorizado para a aplicação do Concílio Vaticano II e poderia, aliás, considerar-se como o último documento do Concílio. A função de juiz requer o conhecimento do fato a ser julgado e o conhecimento da nova lei que "supõe um estudo assíduo, científico, aprofundado e que não se limite a relevar as eventuais variações a respeito da lei anterior, ou a estabelecer-lhe o sentido meramente literal ou filológico, mas que chegue a considerar também a mens legislatoris e a ratio le-

2 JOÃO PAULO II, Alocução ao Tribunal da Rota Romana: A maior função da Sagrada Rota é manifestada pela exemplar qualidade do trabalho realizado, in Acta Apostolica Sedis, vol. 75 (1983), p. 554-559, in L'Osservatore Romano, Edição Semanal em Português, Ano XIV, n. 10 (692), 6 de março de 1983, p. 9. 
gis" para entender o espírito da nova lei. Ao conhecimento segue-se a fidelidade que significa "aceitação sincera, leal e incondicionada da lei legitimamente promulgada". Por isso, o tempo da preparação da legislação já passou e o Código anterior foi revogado, agora a interpretação cabe ao Legislador e a Igreja protege o matrimônio, "mediante o seu contínuo Magistério, suas leis e, em forma particular, pelo ministério do seu poder judiciário"3.

Nessa perspectiva, o discurso em 1980 fundamenta biblicamente a justiça que tem, frente à verdade, uma relação de dependência para verificar nos processos canônicos "a existência ou não dos fatos que, por lei natural, divina ou eclesiástica, invalidam o matrimônio, de tal modo que se possa chegar à emanação de uma sentença verdadeira e justa". Desde o libelo à impostação da defesa, tudo deve ser fonte de verdade; afinal, "não se trata de criar um acontecimento que nunca existiu, mas sim de pôr em evidência e fazer valer um fato verificado no passado e que talvez ainda perdure no presente", para que haja o pronunciamento de uma justa sentença, antecedida pelo voto do defensor do vínculo, com a certeza moral proveniente dos atos e das provas, acompanhado pelo conhecimento da lei e de sua fidelidade a ela, conforme o ensinamento do Concílio sobre a família e auxiliado pelas ciências ${ }^{4}$. Entretanto, é fundamental a referência ao Papa Francisco que conservou a exigência de um processo de natureza judicial para se averiguar a existência ou não da nulidade do matrimônio, não atendendo, desta forma, àqueles que haviam proposto a adoção de um processo de natureza administrativa. ${ }^{5}$

3 JOÃO PAULO II, Alocução ao Tribunal da Rota Romana: A fidelidade é o primeiro e mais importante dever do juiz, in Acta Apostolica Sedis, vol. 76 (1984), p. 643-649, in L'Osservatore Romano, Edição Semanal em Português, Ano XV, $\mathrm{n}^{\mathrm{o}} 6$ (740), 5 de fevereiro de 1984, p. 8.

4 JOÃO PAULO II, Alocução ao Tribunal da Rota Romana: A procura da verdade, suprema norma da justiça, in Acta Apostolica Sedis, vol. 72 (1980), p. 172178, in L'Osservatore Romano, Edição Semanal em Português, Ano XI, n. 7 (533), 17 de fevereiro de 1980, p. 5-6.

5 D. GERALDO - V. J. RIBEIRO, A reforma no processo de nulidade matrimonial e sua gênese no Sínodo dos Bispos, in Revista Eclesiástica Brasileira (REB), vol. 302 (2016), p. 368. 


\section{A raíz antropológica da jurisprudência rotal}

Por ocasião da celebração do $30^{\circ}$ aniversário da Declaração Universal dos Direitos Humanos e do Ano Internacional da Criança, João Paulo II, em seu primeiro discurso ao Tribunal Apostólico da Rota Romana em 1979, reafirmou que a defesa dos direitos humanos é um encargo irrenunciável à Igreja, como um dever da Igreja de ser espelho da justiça. O Direito Canônico, por sua vez, "desempenha função sumamente educativa, individual e social, no intuito de criar uma convivência ordenada e fecunda, em que germine e amadureça o desenvolvimento integral da pessoa humano-cristã". Como sacerdotes da justiça, a observância pelas normas processuais nos tribunais é um respeito à pessoa, manifestando perfil pastoral do direito. Nesta perspectiva, insere-se positivamente também a disciplina penal como instrumento de comunhão, pois, citando Paulo VI, João Paulo II considera que os direitos dos batizados na Igreja estão relacionados com suas obrigações, de modo que o exercício dos seus direitos se concretize na unidade e na solidariedade para o exercício dos valores superiores e do bem comum. Por fim, o discurso salienta que "as palavras direito, juízo e justiça (...) lembram o modelo de uma justiça superior, a justiça de Deus", comportando um esforço formidável de adaptação terminológica e prática naqueles que administram a justiça ${ }^{6}$. Grocholewski, interpretando o pensamento de João Paulo II, afirma que a dignidade da pessoa humana, ancorada no bem, é o fator fundamental do bem comum e critério essencial para todos os programas e sistemas de governo $^{7}$.

Em 1981, o discurso cita diversas vezes o sínodo sobre a família e trata de sua tutela jurídica com origem no matrimônio, "ponto de encontro de várias gerações que mutuamente se ajudam a adquirir maior sabedoria e a humanizar os direitos das pessoas com as restantes exigências da vida social", constituindo-se o fundamento para o bem-

6 JOÃO PAULO II, Alocução ao Tribunal da Rota Romana: A função judicial da Igreja ao serviço da equidade e da caridade, in Insegnamenti di Giovanni Paolo II, vol. II, Libreria Editrice Vaticana, 1979, p. 408-414, in L'Osservatore Romano, Ano X, n. 8 (482), 25 de fevereiro de 1979, p. 1-2.

7 Z. GROCHOLEWSKI, La filosofia del diritto di Giovanni Paolo II, Editrice Falma Edium, Roma, 2002, p. 44. 
estar da própria pessoa e da sociedade. Mesmo diante das graves dificuldades da família na sociedade contemporânea, a instituição matrimonial revela o seu valor insubstituível e a família continua ainda a ser a "escola do mais rico humanismo". É necessário tutelar pela família também na esfera jurídica como comunidade conjugal de vida e amor, sendo que "a estabilidade do vínculo conjugal e a feliz subsistência da comunidade familiar dependem da preparação que os noivos fizeram antes do próprio matrimônio"; preparação esta que seria "influenciada negativamente pelos pronunciamentos ou sentenças de nulidade matrimonial, quando estes fossem obtidos com demasiada facilidade". É necessário ter prudência na aplicação do direito e em seu conceito de inovação, pois "a legítima tutela da família, sempre em favor da pessoa, enquanto a preocupação unilateral em favor do indivíduo pode acabar em prejuízo da pessoa humana em si mesma, além de ser nociva ao matrimônio e à família, bens tanto da pessoa como da sociedade" 8 .

Francisco também tratou do mesmo argumento em Mitis Iudex Dominus Iesus e Mitis et misericors Iesus ${ }^{9}$, pois na sequência da introdução, para evitar equívocos ou distorções, teve o cuidado de esclarecer que a reforma por ele proposta não tem por objetivo favorecer a nulidade do matrimônio, mas, sim, a celeridade dos processos. Ora, se de um lado é preciso garantir que a decisão sobre a validade ou nulidade do matrimônio seja proferida em tempos razoáveis (celeridade), por outro lado é fundamental que tal decisão esteja sempre em conformidade com a verdade ${ }^{10}$.

Ao considerar a função do juiz, que dirime questões e problemas relativos aos direitos subjetivos, manifesta-se a comunhão com a Igreja universal que defende e ilumina a natureza humana como instrumento do amor divino, como missão evangélica, eclesial e sacerdotal,

8 JOÃO PAULO II, Alocução ao Tribunal da Rota Romana: Salvaguardar os valores do matrimônio para tutelar o grande bem da família, in Acta Apostolica Sedis, vol. 73 (1981), p. 228-234, in L'Osservatore Romano, Edição Semanal em Português, Ano XII, n. 6 (584), 8 de fevereiro de 1981, p. 1 e 3.

9 FRANCISCO. Cartas apostólicas em forma de motu proprio Mitis Iudex Dominus Iesus e Mitis et misericors Iesus sobre nulidade do matrimônio, Edições CNBB, Brasília, 2015.

10 D. GERALDO, - V. J. RIBEIRO, A reforma no processo de nulidade, p. 362. 
permanecendo ao mesmo tempo como ação humanitária e social. O aspecto teológico na elaboração das sentenças oferece a visão do matrimônio cristão querido por Deus como imagem divina, como consagração a Deus e como modelo e perfeição de toda a união conjugal humana. De fato, a aplicação do novo Código pode correr o risco de interpretações imprecisas e incoerentes, mas a superação com serenidade, mediante um estudo aprofundado, sem ceder a superficial mentalidade permissiva que não tem na devida conta as inderrogáveis exigências do matrimônio como sacramento. Neste ponto, João Paulo II reafirma que as sentenças da Rota Romana representam uma fonte de jurisprudência para as atividades dos Tribunais eclesiásticos regionais e diocesanos ${ }^{11}$.

O tema em 1998 abordou a configuração e a colocação da administração da justiça ordenada ao fim sobrenatural da Igreja que é a redenção dos homens. Nessa perspectiva é exercida a justiça no corpo eclesial, do qual o juiz é autêntico sacerdos iuris com um ofício na caridade, na unidade, na missão de bom pastor, representado na necessidade de que as causas matrimoniais sejam levadas a cabo com a seriedade e a rapidez requeridas pela sua própria natureza. Outro aspecto nesta consideração é a ação do juiz em diálogo interdisciplinar com as ciências, mas fiel à verdade revelada sobre o matrimônio ${ }^{12}$.

Ao referir-se, em 1989, sobre o novo Código de Direito Canônico, atribuiu grande importância ao direito de defesa que todo ser humano possui, conforme o cânon 221. Tal direito, nas causas matrimoniais, é exercido segundo as justas disposições da lei, cuja função não é limitar, mas regular de modo que não possa degenerar em abuso ou obstrucionismo da justiça, garantindo ao mesmo tempo a concreta possibilidade de exercê-lo. Para garantir ainda mais o direito de defe-

11 JOÃO PAULO II, Alocução ao Tribunal da Rota Romana: $O$ vosso trabalho é judiciário, mas a vossa missão é fundamentalmente evangélica, eclesial e sacerdotal, in Acta Apostolica Sedis, vol. 78 (1986) p. 921-925, in L'Osservatore Romano, Edição Semanal em Português, Ano XVII, n. 8 (848), 23 de fevereiro de 1986, p. 1, 3 .

12 JOÃO PAULO II, Alocução ao Tribunal da Rota Romana: Salvaguardar a imutabilidade da lei divina e a estabilidade da norma canônica, in Acta Apostolica Sedis, vol. 85 (1993), p. 140-143, in L'Osservatore Romano, Edição Semanal em Português, Ano XXIII, n. 5, 2 de fevereiro de 1992, p. 11. 
sa, o tribunal tem a obrigação de publicar a sentença e indicar às partes os modos pelos quais a mesma sentença pode ser impugnada. Os assuntos sob segredo de ofício advêm quando podem prejudicar alguém; com efeito, os fiéis ao dirigem-se ordinariamente ao tribunal eclesiástico para resolver o próprio problema de consciência podem dizer algumas coisas que de outro modo não diriam. Aqui, os assuntos sob segredo não contrariam o direito de defesa, mas protegem a intimidade e a unidade da comunidade ${ }^{13}$.

Em 1994, a alocução fez alusão à encíclica Veritatis splendor que aborda a relação entre o esplendor da verdade e o da justiça e a necessidade de que a justiça humana seja imagem do esplendor da justiça divina e da verdade praticada segundo a reta razão. É legítimo falar do splendor iustitiae e também do splendor legis. Com efeito, evitando a instrumentalização da lei, o fiel que "reconhece, sob o impulso do Espírito, a necessidade de uma profunda conversão eclesiológica, transformará a afirmação e o exercício dos seus direitos em aceitação dos deveres de unidade e de solidariedade". A atividade do juiz, nesta linha de pensamento, é um ministério na verdade sob a luz de Deus; e se os administradores da lei tiverem uma atitude de plena disponibilidade às exigências da verdade, os fiéis poderão conservar a certeza de que a sociedade eclesial desenvolve a sua vida sob o regime da lei, pois os direitos eclesiais são protegidos pela própria lei. Por isso, a lei é ocasião de uma resposta amorosa à vontade de Deus que, na sua observância, exige sacrifícios, não podendo ser dispensada por um falso conceito de misericórdia. A autoridade legítima, por sua vez, estimula a empenhar-se e promover a correta formação da consciência pessoal porque, se bem formada, a consciência adere naturalmente à verdade e percebe em si mesma um princípio de obediência, que a impele a adequar-se à diretriz da lei (Veritatis splendor, n. 75) ${ }^{14}$.

13 JOÃO PAULO II, Alocução ao Tribunal da Rota Romana: A Lei garante o exercício do direito da defesa e regula-o para evitar abuso ou obstrucionismo, in Acta Apostolica Sedis, vol. 81 (1989), p. 922-927, in L'Osservatore Romano, Edição Semanal em Português, Ano XX, n. 7 (1003), 12 de fevereiro de 1989, p. 5.

14 JOÃO PAULO II, Alocução ao Tribunal da Rota Romana: No Ano da Família emergem com clareza cada vez maior os riscos que a instituição familiar corre por causa de uma "compreensão” mal entendida, in Acta Apostolica Sedis, vol. 
Por fim, João Paulo II apresentou, em 1995, a centralidade da pessoa humana no exercício do ministerium iustitiae e o dever de conjugar a justiça com a consciência individual. Daí resulta a importância e a necessidade de uma adequada visão antropológica, sendo que os problemas provocados por conceitos errôneos representam a natureza e a existência humanas "fechada aos valores e significados que transcendem o dado imanente e que permitem ao homem orientar-se para o amor de Deus e do próximo como sua vocação última". Tal concepção irá "repercutir negativamente na administração da justiça e, de modo particular, ainda mais gravemente, no desenvolvimento das causas de nulidade do matrimônio". É preciso recordar a doutrina do pecado original, a redenção em Cristo, o reconhecimento da altíssima nobreza humana e que certas exigências do Evangelho podem trazer benefícios essenciais para o crescimento do próprio homem em Cristo. Deste modo, não há dúvida que uma correlação entre lei canônica e consciência do sujeito se põe também no âmbito do foro externo. Ora, "se é verdade que o homem deve agir em conformidade com o juízo da própria consciência, é de igual modo verdade que o juízo da consciência não pode pretender estabelecer a lei; só pode reconhecê-la e fazê-la própria" ${ }^{15}$. Afirma Wilk que na antropologia de Wojtyla a definição de ser humano vinha de Boécio com o conceito de suppositum, ou seja, a pessoa é o homem concreto, individua substancial6. Visto que a lei encontra a sua atuação ao introduzir-se em cada caso concreto, o juiz, prudentemente, desempenha sua função como aquele que diz o direito, ajudado pelo progresso das ciências humanas e iluminado por uma visão filosófica e teológica clara e autenticamente fundada ${ }^{17}$.

86 (1994), p. 947-952, in L'Osservatore Romano, Edição Semanal em Português, Ano 25, n. 6 (1261), 5 de fevereiro de 1994, p. 5.

15 JOÃO PAULO II, Alocução ao Tribunal da Rota Romana: A justiça e a consciência individual, in Acta Apostolica Sedis, vol. 87 (1995), p. 1013-1019, in S. GOMES (Org.), Alocuções dos Papas Paulo VI e João Paulo II ao Tribunal da Rota Romana, Lisboa: Universidade Católica, 2006, p. 233-239.

16 R. K. WILK, La persona umana nella filosofia di Karol Wojtyla, in Angelicum, vol. 82 (2005), Fasc. 2, p. 375.

17 JOÃO PAULO II, Alocução ao Tribunal da Rota Romana: Ter em conta a peculiaridade de cada caso no processo de nulidade de matrimônio, in Acta Apostolica Sedis, vol. 88 (1996), p. 773-777, in L'Osservatore Romano, Edição Semanal em Português, Ano XXVII, n. 4 (1364), 27 de janeiro de 1996, p. 7. 


\section{A jurisprudência matrimônial como um serviço à Igreja e à humanidade}

As reflexões de João Paulo II sobre a jurisprudência rotal em relação ao matrimônio demonstram que esse Tribunal Apostólico exerce um serviço à Igreja e à humanidade. Em 1982 recordou a Exortação Apostólica Familiaris consortio e citou o Concílio Vaticano II que reconheceu no matrimônio um pacto de amor, supondo "a escolha consciente e livre, com que o homem e a mulher acolhem a íntima comunidade de vida e de amor, querida pelo próprio Deus". Este é o consentimento matrimonial que representa compromisso, vínculo de amor, ato eclesial, funda a Igreja doméstica e constitui uma realidade sacramental. No consentimento, sob o aspecto jurídico, estas obrigações são mais facilmente definidas, se expressas como um direito que se cede do que como uma obrigação que se assume, caracterizado existencialmente como dom. Nas atividades do poder judiciário canônico, o primeiro trabalho do tribunal é respeitar o consentimento matrimonial dos cônjuges e as palavras do ser humano, pois são capazes de um ato definitivo. Daqui brota a necessidade de reconhecer no juiz a grandeza de sua função, o dever das observações a favor do matrimônio pelo defensor do vínculo, o empenho do promotor de justiça a favor de bem comum e considerar os trabalhos dos advogados como eclesial e a favor dos pobres ${ }^{18}$. Nesse sentido, os tribunais não podem justificar conceito de "caridade pastoral" como todo esforço rumo à declaração da nulidade do vínculo matrimonial sem referência à justiça e à verdade, tornando-se mero instrumento técnico ao serviço de qualquer interesse subjetivo sem considerar a relevância quer para as partes, quer para toda a assembleia eclesial ${ }^{19}$

Em 1991, o tema fundamentou-se na afirmação de que o matrimônio é uma instituição de direito natural com características inscritas no ser humano, e o vínculo que vem a se criar é superior a todos os

18 JOÃO PAULO II, Alocução ao Tribunal da Rota Romana: A vossa missão a serviço do amor consiste em reconhecer o pleno valor do matrimônio, in Acta Apostolica Sedis, vol. 74 (1982), p. 449-454, in L'Osservatore Romano, Edição Semanal em Português, Ano XIII, n. 6 (636), 7 de fevereiro de 1982, p. 3.

19 D. GERALDO, A teologia do direito matrimonial nas alocuções de Bento XVI ao tribunal da rota romana, in Horizonte, v. 13, n. 38 (abr./jun 2015), p. 1106. 
outros vínculos inter-humanos, superior ao vínculo dos filhos para com os pais. "Por este motivo, o homem deixará o pai e a mãe para se unir à sua mulher; e os dois serão uma só carne" $(\mathrm{Gn} 2,24)$. De fato, "por ser uma realidade profundamente radicada na própria natureza humana, o matrimônio é assinalado pelas condições culturais e históricas de cada povo". Na relação com o direito romano, "a fé cristã, ao mesmo tempo em que introduzia o valor da indissolubilidade do vínculo matrimonial, encontrava na reflexão jurídica romana sobre o consentimento o instrumento para exprimir o princípio fundamental que está na base da disciplina canônica sobre esta matéria". Na cultura hodierna reconhece-se, positivamente, a igual dignidade entre o homem e a mulher, numa perspectiva personalista do matrimônio. Por outro lado, o consumismo menospreza a instituição matrimonial, torna absoluto o conceito de liberdade que conduz ao divórcio, renuncia às próprias responsabilidades e logo pede a nulidade matrimonial, transformando a celebração sacramental apenas como ato social. Por outro lado, a tutela do matrimônio válido e o caráter pastoral do direito processual representam o sinal da continuidade com a tradição e da abertura às novas instâncias em que se coloca a nova legislação matrimonial, fundada sobre três eixos: consentimento matrimonial, habilidade das pessoas e a forma canônica com "um notável espaço à responsabilidade das Conferências Episcopais ou dos pastores das Igrejas particulares, para adaptações conformes com a diversidade das culturas e com a variedade das situações pastorais" 20 .

A nova codificação canônica valorizou a perspectiva conciliar sobre o matrimônio e a definição de íntima comunidade de vida e amor com a dimensão jurídica específica, assim considerou João Paulo II em 1997. Deste modo, o valor jurídico não se justapõe, como corpo estranho à realidade interpessoal do matrimônio, mas lhe constitui uma dimensão intrínseca, pois as relações entre os cônjuges, bem como entre os pais e os filhos, são constitutivamente relações de justiça e, por isso, são realidades em si mesmas relevantes sob o ponto de

20 JOÃO PAULO II, Alocução ao Tribunal da Rota Romana: É preciso repropor integralmente a mensagem evangélica sobre o matrimônio, in Acta Apostolica Sedis, vol. 83 (1991), p. 947-953, in L'Osservatore Romano, Edição Semanal em Português, Ano XXII, n. 7 (1107), 28 de janeiro de 1991, p. 3. 
vista jurídico. Tal realidade expressa uma visão antropológica e teológica subjacente; contrário ao individualismo e ao relativismo. "Há certamente uma essência do matrimônio, descrita pelo c. 1055 que impregna toda a disciplina matrimonial, como é demonstrado pelos conceitos de propriedade essencial, elemento essencial, direitos e deveres matrimoniais essenciais". Contudo, permanece a tarefa do juiz de determinar, "também com a ajuda da ciência humana, aquele mínimo abaixo do qual não se poderia falar de capacidade nem de consentimento, suficiente para um verdadeiro matrimônio"21. Para Grocholewski, João Paulo II considera a pessoa humana em sua dimensão integral, ou seja, uma realidade que não se repete no ser, no agir, no intelecto, na vontade, na consciência e, principalmente, no coração ${ }^{22}$.

Em 1999, constatou João Paulo II, que no mundo contemporâneo aparece a difundida deterioração do sentido natural e religioso das núpcias, com reflexos na esfera, tanto pessoal como pública. Considerar o amor conjugal como sentimento é declarar o falimento da família. O amor conjugal é mais do que sentimento; é "um empenho para com a outra pessoa; empenho que se assume com um preciso ato de vontade (...) tornando-o conjugal, uma vez dado e aceito o empenho por meio do consentimento, o amor torna-se conjugal, e nunca perde este caráter". Em se tratando da forma jurídica do matrimônio, a alocução afirma que "representa uma conquista de civilização, pois the confere relevância e também eficácia diante da sociedade, que, por conseguinte, assume a sua tutela". Isto impossibilita o reconhecimento jurídico como união matrimonial às uniões de fato e às uniões das pessoas do mesmo sexo. Na verdade, "a lei canônica reconhece a todo homem a faculdade de contrair matrimônio como uma faculdade que só pode ser exercida por aqueles qui iure non prohibentur, em primeiro lugar, e aqueles que têm suficiente maturidade psíquica na dúplice

21 JOÃO PAULO II, Alocução ao Tribunal da Rota Romana: Os reflexos jurídicos dos aspectos personalistas do matrimônio, in Acta Apostolica Sedis, vol. 89 (1997), p. 486-489, in L'Osservatore Romano, Edição Semanal em Português, Ano XXVIII, n. 6, 8 de fevereiro de 1997, p. 5.

22 Z. GROCHOLEWSKI, La filosofia del diritto di Giovanni Paolo II, p. 43. 
componente intelectiva e volitiva, juntamente com a capacidade de cumprir os ônus essenciais da instituição matrimonial"23.

Ao fazer referência novamente à Familiaris consortio em 2000, colocou o sentido equivocado da "liberdade concebida não como capacidade de realizar a verdade do projeto de Deus sobre o matrimônio e a família, mas como força autônoma de afirmação, não raramente contra os outros, para o próprio bem-estar egoísta". O matrimônio tem outra perspectiva; está radicado "na doação pessoal e total dos cônjuges e exigida pelo bem dos filhos e a indissolubilidade do matrimônio, encontra a sua verdade última no desígnio que Deus manifestou na Revelação". É inegável que a sociedade tem dificuldade em aceitar a indissolubilidade do vínculo matrimonial, mas a dificuldade não equivale à negação. Para afirmar a exclusão de uma propriedade essencial ou a negação de uma finalidade fundamental do matrimônio, é necessário verificar um positivo ato de vontade. Portanto, nem mesmo o Romano Pontífice pode dissolver um matrimônio rato e consumado, indissolúvel por direito divino "como doutrina a ser conservada de maneira definitiva, embora esta não tenha sido declarada de forma solene mediante um ato definitório" 24 .

Diante da tendência de confinar o matrimônio e a família ao mundo privado, em 2001 reafirma o ensinamento tradicional sobre a dimensão natural evidenciada pela razão e confirmada pela revelação, pois "o próprio Deus é o autor do matrimônio, que dotou de vários bens e fins" (Gaudium et Spes n. 48). Sem o conceito de natureza, a cultura perde seu fundamento objetivo e está à mercê do livre arbítrio e do poder, ou seja, "o matrimônio é natural não porque é causado pela necessidade dos princípios naturais, mas enquanto realidade para a

23 JOÃO PAULO II, Alocução ao Tribunal da Rota Romana: A gravidade e o caráter insubstituível de princípios basilares revelam como é incongruente a pretensão de atribuir uma realidade "conjugal" à união entre pessoas do mesmo sexo, in Acta Apostolica Sedis, vol. 90 (1998), p. 781-785, in L'Osservatore Romano, Edição Semanal em Português, no 5 (1520), 30 de janeiro de 1999, p. 23.

JOÃO PAULO II, Alocução ao Tribunal da Rota Romana: O matrimônio sacramental ratificado e consumado jamais pode ser dissolvido, nem sequer pelo poder do Romano Pontífice, in Acta Apostolica Sedis, vol. 92 (2000), p. 350-355, in L'Osservatore Romano, Edição Semanal em Português, n. 5 (1572), 29 de janeiro de 2000, p. 4. 
qual a natureza se inclina, completada mediante o livre arbítrio" como caminho pelo qual se pode manifestar a autêntica riqueza e variedade de tudo o que é humano na fidelidade às exigências da própria natureza. Na realidade, "o bem dos cônjuges, a procriação e a educação da prole estão intrinsecamente presentes na masculinidade e na feminilidade e esta índole teleológica é decisiva para compreender a dimensão natural da união". Tendo como propriedades essenciais a unidade e a indissolubilidade, a união conjugal não é fundamentada unicamente nas qualidades pessoais, nos interesses ou nas atrações. O consentimento matrimonial é mais bem compreendido em relação à dimensão natural da união do que em relação a uma lei positiva ou cultural. No entanto, o matrimônio não está isento da lógica da Cruz de Cristo; necessita de esforços e sacrifícios, comporta inclusivamente dores e sofrimentos, mas a aceitação da vontade de Deus não impede uma plena e autêntica realização pessoal, na paz e na serenidade do espírito ${ }^{25}$. Portanto, para Kaczynski, o conceito de lei natural em João Paulo II depende do conceito de pessoa humana e da sua capacidade de autodeterminação ${ }^{26}$.

Em 2002, o discurso propõe superar a visão da indissolubilidade como um limite à liberdade dos contraentes, como se fosse uma lei extrínseca ao matrimônio e a imposição de uma norma contra as legítimas expectativas de uma realização da pessoa. Nesta perspectiva, o matrimônio indissolúvel seria característico apenas dos crentes e não poderia ser colocado à sociedade civil, acreditando que a indissolubilidade não seria uma norma jurídica natural, mas um simples ideal. Contudo, é "a dimensão natural da união, e mais concretamente a natureza do homem plasmada pelo próprio Deus, que fornece a indispensável chave de leitura das prioridades fundamentais do matrimônio". Tais aspectos doutrinais sobre a indissolubilidade são ensinados, esclarecidos e defendidos pelo ensinamento da Igreja, mas é ainda

25 JOÃO PAULO II, Alocução ao Tribunal da Rota Romana: A cultura individualista invasora tende a circunscrever e confinar o matrimônio e a família ao mundo privado, in Acta Apostolica Sedis, vol. 93 (2001), p. 358-365, in L'Osservatore Romano, Edição Semanal em Português, Ano XXXII, n. 6 (1626), 10 de fevereiro de 2001, p. 6-7.

26 E. KACZYNSKI, Legge naturale e diritti umani in Karol Wojtyla, in Angelicum 82 (2005), Fasc. 2, p. 288. 
mais importante o testemunho dos casais. A atividade judiciária e a declaração de nulidade matrimonial, por sua vez, "dá paz às consciências, mas tal declaração - o mesmo vale para a dissolução do matrimônio ratificado e não consumado e para o privilégio da fé - deve ser apresentada e realizada em um contexto eclesial profundamente a favor do matrimônio indissolúvel e da família nele fundada". Nesse sentido, a produção acadêmica e programas na mídia sobre a família, as celebrações de matrimônio e de aniversário matrimonial contribuem para que o tema seja colocado na sociedade civil como um bem público e como célula-mãe da sociedade ${ }^{27}$.

Depois de insistir nos discursos anteriores sobre a fundamentação do matrimônio no direito natural, em 2003 relaciona o matrimônio dos batizados com o mistério de Deus que, na Aliança definitiva em Cristo, assume a dignidade de sacramento. No entanto, a dimensão natural e a relação com Deus não são duas realidades justapostas, mas intimamente ligadas, como a verdade sobre o homem e a verdade acerca de Deus, superando qualquer dicotomia que pretenda separar os aspectos naturais dos aspectos religiosos, como se houvesse um profano e outro sagrado. Por ser uma só carne (Gn 2, 24), o homem e a mulher, quer na sua ajuda recíproca quer na sua fecundidade, participam em algo que é sagrado e religioso: figura da encarnação do Verbo de Deus. O próprio Cristo restabeleceu o desígnio primordial sobre o matrimônio (Mt 19, 1-12), readquirindo a santidade original e inserindo-o no mistério da aliança, propiciando o conceito de Igreja doméstica. Contudo, a mentalidade contemporânea afasta o matrimônio dos valores religiosos e autônomo de Deus. No entanto, a razão última do amor fiel é porque Deus é fiel, sendo necessário recorrer a Deus e em Cristo para compreender a fecundidade e a alegria da fidelidade. Esta consideração sobre a sacramentalidade do matrimônio põe em relevo a transcendência da função judiciária canônica, que não significa a banalização do pacto núpcial, mas une o judiciário com a economia salvífica e poderá confirmar o matrimônio existente e pedir sua reconci-

27 JOÃO PAULO II, Alocução ao Tribunal da Rota Romana: O bem da indissolubilidade é o bem próprio do matrimônio, in Acta Apostolica Sedis, vol. 94 (2002), p. 340-346, in L'Osservatore Romano, Edição Semanal em Português, Ano XXXIII, n. 5 (1677), 2 de fevereiro de 2002, p. 7 e 10. 
liação. Por fim, “a Igreja católica sempre reconheceu os matrimônios entre os nãos batizados, que se tornam sacramento cristão mediante o batismo dos cônjuges, e não tem dúvidas sobre a validade do matrimônio de um católico com uma pessoa não batizada, se for celebrado com a devida dispensa",28.

\section{A jurisprudência rotal e o necessário diálogo com a ciência}

Para Bogood, João Paulo II era fascinado pela ciência e seu interesse era ainda maior explicado pela insistência para uma abertura à fé $^{29}$. O discurso de 1987 manifestou uma atenção com o elevado número de declarações de nulidade matrimonial sobre a incapacidade psíquica. $\mathrm{O}$ discurso reconheceu os progressos nas ciências psicológicas e psiquiátricas e suas contribuições nos processos jurídicos, possibilitando apreciar a resposta humana à vocação matrimonial de modo mais preciso e diferenciado de quanto seria permitido unicamente pela filosofia e a teologia. Contudo, fez advertência à impossibilidade de que as ciências humanas ofereçam uma visão integral do homem, necessitando que o perito e o juiz tenham como base do trabalho, além do diálogo, a antropologia teológica, o homem criado à imagem e semelhança de Deus, para que as respectivas competências sejam respeitadas. "Se, ao contrário, o horizonte dentro do qual se move o perito, psiquiatra ou psicólogo, é oposto ou fechado àquele dentro do qual se move o canonista, o diálogo e a comunicação podem tornar-se fonte de confusão e de mal-entendido", pois só a incapacidade, e não somente a dificuldade em prestar o consentimento e em realizar uma verdadeira comunidade de vida e amor, torna nulo o matrimônio, ou seja, "uma séria forma de anomalia que, qualquer que seja a sua definição, deve afetar substancialmente as capacidades de entender e/ou de querer do contraente". Deste modo, o trabalho do juiz é, na verdade

28 JOÃO PAULO II, Alocução ao Tribunal da Rota Romana: É preciso redescobrir a dimensão transcendente e intrínseca à verdade plena sobre o matrimônio e a família, in Acta Apostolica Sedis, vol. 95 (2003), p. 393-397. in L'Osservatore Romano, Edição Semanal em Português, Ano XXXIV, n. 6 (1730), 8 de fevereiro de 2003 , p. 3.

29 A. BAGGOD, John Paul II's discrete eye for science, in Angelicum 82 (2005), Fasc. 2, p. 355. 
e na caridade, dialogal com as ciências e em comunhão com a inteira atividade pastoral da Igreja ${ }^{30}$.

Em 1988, destaca a missão do Defensor do Vínculo nos processos de incapacidade psíquica com a "obrigação de propor e expor tudo o que razoavelmente possa ser aduzido contra a nulidade", dado que o matrimônio se refere ao bem público da Igreja, sua ausência torna nulos os atos processuais. O conceito de normalidade para as ciências psicológicas e psiquiátricas pode parecer contrário à normalidade para da ação judicial canônica que se inspira na visão integral da pessoa, compreendendo também moderadas formas de dificuldade psicológica com a consequente chamada a caminhar segundo o Espírito, mesmo entre as tribulações e à custa de renúncias e sacrifícios. "Não é raro que as análises psicológicas e psiquiátricas feitas nos contraentes, em vez de considerarem a natureza e o grau dos processos psíquicos referentes ao consentimento matrimonial e à capacidade da pessoa em assumir as obrigações essenciais do matrimônio, limitem-se a descrever os comportamentos dos contraentes nas diversas idades da vida, colhendo as suas manifestações anormais" com a antecipada conclusão favorável à nulidade. O Defensor do vínculo tem a missão de referenciar a adequada visão antropológica da normalidade para confrontar com ela os resultados das perícias e indicar ao juiz as eventuais distorções para que se chegue à verdade ${ }^{31}$.

\section{A pastoralidade da jurisprudência rotal}

A alocução de 1990 tratou da dimensão pastoral do direito canônico e das relações entre pastoral e direito na Igreja que "encontra assim o seu sólido fundamento na eclesiologia conciliar, segundo a

30 JOÃO PAULO II, Alocução ao Tribunal da Rota Romana: O Juiz não se deixe sugestionar por perícias baseadas em premissas antropológicas inaceitáveis, in Acta Apostolica Sedis, vol. 79 (1987), p. 1453-1459, in L'Osservatore Romano, Edição Semanal em Português, Ano XVIII, n. 7, 15 de fevereiro de 1987, p. 1011.

31 JOÃO PAULO II, Alocução ao Tribunal da Rota Romana: $O$ respeito da visão cristã do matrimônio, in Acta Apostolica Sedis, vol. 80 (1988), p. 1178-1185, in L'Osservatore Romano, Edição Semanal em Português, Ano XIX, n. 7, 14 de fevereiro de 1988, p. 12. 
qual os aspectos visíveis da Igreja estão inseparavelmente unidos aos aspectos espirituais, formando uma única realidade complexa, comparável ao mistério do Verbo encarnado" e fazendo com que as leis e as instituições canônicas estejam adequadas ao bem das almas. Seria um erro considerar "que só as exceções às leis, o eventual não recurso aos processos e às sanções canônicas e a rapidez das formalidades jurídicas têm verdadeira relevância pastoral". A pastoralidade não exige do direito que seja menos jurídico e nem exclui a justiça e a misericórdia. Aplicado este princípio ao processo de nulidade matrimonial, sendo que o processual é também pastoral, não pode ser considerada como misericórdia a adaptação do direito às necessidades individuais, pois "as vias que se distanciam da justiça e da verdade acabam por contribuir para afastar as pessoas de Deus, obtendo o resultado oposto àquele que em boa-fé se procurava". O processo justo é um direito dos fiéis e constitui, ao mesmo tempo, a exigência do bem público da Igreja, conduzindo à justiça substancial ${ }^{32}$. $\mathrm{Na}$ realidade, afirma Francisco, misericórdia e justiça não são dois aspectos em oposição, mas duas dimensões de uma única realidade que se desenvolve progressivamente até chegar ao ápice do amor ${ }^{33}$. Amenta afirma que Francisco faz referência à Carta aos Romanos $(13,10)$, pois a mera observância da lei não pode ser considerada justiça ${ }^{34}$.

Em 2004, João Paulo II expõe que o principal trabalho no Tribunal da Rota é sobre o matrimônio e reflete o âmbito jurídicopastoral de que este goza a favor do direito, bem como a presunção de validade em caso de dúvida, pois algumas críticas afirmam "se não seria mais justo presumir a nulidade do matrimônio contraído, em vez da sua validade". O conceito de favor matrimonii transcende a presunção de validade canônica, pois o apoio ao matrimônio inspira todas as atividades da Igreja por aquilo que é união conjugal e sua importância às pessoas, às comunidades e à sociedade. O favor iuris de que goza o matrimônio implica a presunção da sua validade, enquanto não se

32 JOÃO PAULO II, Alocução ao Tribunal da Rota Romana: O valor pastoral do direito na Igreja, in Acta Apostolica Sedis, vol. 82 (1990), p. 872-877, in L'Osservatore Romano, Edição Semanal em Português, Ano XXI, n. 4 (1053), 28 de janeiro de 1990, p. 3.

33 FRANCISCO, Misericórdia Vultus, São Paulo, Paulinas, 2015, n.20.

34 P. AMENTA, Misericodioso e giusto, Tau Editrice, Todi, 2017, p. 39. 
prova o contrário, pois nem toda falência da vida conjugal pode receber a nulidade que, segundo a experiência humana assinalada pelo pecado, um matrimônio válido pode falir por causa do recurso errôneo à liberdade dos próprios cônjuges. Daí a importância da investigação pré-matrimonial realizada pelo pároco, não como algo burocrático, mas na convicta verdade sobre este sacramento, sem o pessimismo antropológico e teológico, com renovada confiança de que o ser humano é capaz de um ato definitivo e irrevogável. Por fim, "sem nada tirar das contribuições válidas que podem derivar da sociologia, da psicologia ou da psiquiatria, uma consideração autenticamente jurídica do matrimônio exige a visão metafísica da pessoa humana e do relacionamento conjugal" 35 .

Ao recordar o encontro pela paz que aconteceu em Assis, em 1993, João Paulo II discorreu sobre o direito, a justiça e a paz que reciprocamente se integram. Citou o jurista Francesco Carnelutti, distinguindo entre direito e justiça como relação e não identificação, pois o direito é o meio e a justiça o fim para se viver em paz. Por sua vez, "o direito na Igreja, como de resto nos Estados, é garantia de paz e instrumento para a conservação da unidade, ainda que não em sentido de imobilismo". Nesta perspectiva, coloca-se a legislação canônica "que transcende o aspecto exterior da Igreja para alcançar a dimensão mais íntima da sua vida sobrenatural"; acentuando, por outro lado, a grave situação da não observância da lei ou de livre interpretação. Para tanto, foi instituído o Pontifício Conselho para a Interpretação dos Textos Legislativos, mas, no cotidiano junto ao Povo de Deus, "se verificam situações, nas quais a interpretação e a aplicação da Lei canônica são confiadas àqueles a quem, na Igreja, incumbe o poder tanto executivo como judiciário (...) de modo particular à Rota Romana". Contudo, essa hermenêutica em sentido amplo requer que o significado das palavras seja considerado, no texto e no contexto, dentro da tradição canônica. Deste modo, fazer com que a lei canônica ceda ao capricho ou à

35 JOÃO PAULO II, Alocução ao Tribunal da Rota Romana: A instituição matrimonial é uma realidade pessoal indissolúvel elevada à dignidade de sacramento cristão, in Acta Apostolica Sedis, vol. 96 (2004), p. 348-352, in L'Osservatore Romano, Edição Semanal em Português, n. 6 (1782), 7 de fevereiro de 2004, p. 3. 
imaginação interpretativa em nome do conceito de humanização da lei ou pastoralidade, significaria mortificar a própria dignidade do ho$\mathrm{mem}^{36}$.

O último discurso de João Paulo II ao Tribunal Rotal, em 2005, tratou da atividade dos agentes jurídicos nos Tribunais eclesiásticos não condizentes com a retidão moral. Tal atitude pode "induzir as partes a recorrer a vários tipos de falsidade e até mesmo de corrupção, com a finalidade de alcançar uma sentença favorável”, mas a legislação canônica tem uma reação contrária e a este procedimento (Cf. CIC-1983 cc. $1389,1391,1457$ e 1488-1489). Outro problema nos tribunais é a postura que considera nulo todo matrimônio fracassado, optando apenas por uma aparência processual que, certamente, não constitui a solução pastoralmente válida dos problemas levantados pelas crises matrimoniais. A busca pela verdade no processo canônico, sua verdadeira pastoralidade, impele também os bispos que não podem ser omissos, ao considerar o processo de nulidade matrimonial uma questão meramente "técnica", confiando tudo aos seus juízes vigários (Cf. CIC-1983 cc. 391, 1419 e 1423 §1). "É preciso resistir ao medo da verdade, que por vezes pode nascer do temor de ferir as pessoas", fruto da falsa compaixão ou da falsa postura de pensamento. Com efeito, pretende-se separar as leis da Igreja dos ensinamentos magisteriais, como dois setores distintos, dos quais o primeiro seria o único a ter uma força juridicamente vinculante, enquanto o segundo teria um valor meramente orientador ou exortativo. No entanto, tal postura representa uma hermenêutica seletiva e contrária à Constituição Dogmática Dei Verbum 10,2 ou motivada pela falsa pressa processual que prejudicará o trabalho de se chegar à verdade do vínculo matrimonial ${ }^{37}$.

36 JOÃO PAULO II, Alocução ao Tribunal da Rota Romana: A interpretação autêntica e verdadeira da lei, in Acta Apostolica Sedis, vol. 85 (1993), p. 12561260, in L'Osservatore Romano, Edição Semanal em Português, Ano XXIV, n. 7 (1110), 14 de fevereiro de 1993, p. 16.

37 JOÃO PAULO II, Alocução ao Tribunal da Rota Romana: $A$ dimensão moral dos agentes jurídicos e o seu dever de se adaptar à verdade sobre o matrimônio, in Acta Apostolica Sedis, vol. 97 (2005), p. 164-166, in L'Osservatore Romano, Edição Semanal em Português, Ano XXXVI, n. 6, 5 de fevereiro de 2005, p. 5. 


\section{Conclusão}

Pelo número de nulidade por causa de grave falta de discrição de juízo, as alocuções de João Paulo II ao Tribunal Apostólico da Rota Romana oferecem um substancial reconhecimento do progresso nas ciências psicológicas e psiquiátricas como contribuição nos processos jurídicos. Adverte, porém, para a impossibilidade que essas ciências oferecem de uma visão integral do homem. É necessário que o perito e o juiz tenham como base o diálogo e a antropologia comum, respeitando as respectivas competências e a visão cristã do matrimônio, na colaboração interdisciplinar e à luz da antropologia cristã. O respeito da visão cristã do matrimônio faz com que o Defensor do vínculo colabore na busca da verdade e que os conceitos da psicologia e psiquiatria sejam verificados à luz da antropologia cristã, sabendo que há sempre o risco de falência vocacional pelo mau uso da liberdade.

Neste sentido, ao julgar o matrimônio, o tribunal busca a justiça, condição necessária para a paz e elemento indispensável para a unidade, pois a relação entre o esplendor da verdade e o da justiça são quesitos para a plena realização humana. Há sempre a advertência ao perigo da instrumentalização da justiça para interesses egoístas e da falsa concepção de misericórdia que retira a centralidade do bem à pessoa humana no exercício do ministerium iustitiae e o dever de conjugar a justiça com a consciência individual que respeita os limites de uma vida social.

Consequentemente, João Paulo II, como um defensor da pessoa e dos seus direitos, aprofunda nas alocuções os conceitos fundamentais acerca da verdadeira e genuína natureza dos processos de nulidade de matrimônio e a tarefa própria do juiz canônico de ocupar-se da peculiaridade de cada um dos casos no seu contexto cultural, ecoando os aspectos personalistas do matrimônio, tais como a indissolubilidade do vínculo, o consentimento, a maturidade psicológica, a liberdade e a consciência. As relações interpessoais (conjugal, paternal e filial) implicam amor devido que constitui, também, uma relação de justiça.

Tal relação tem efeitos sobre o matrimônio-sacramento, ratificado e consumado, que jamais poderá ser dissolvido. Porém, a cultura individualista tende a circunscrever e confinar o matrimônio e a famí- 
lia ao mundo privado, possibilitando qualquer forma de rompimento do vínculo motivada por um desejo ilimitado de direitos que não reconhece os deveres. $\mathrm{O}$ ensinamento sobre a dimensão natural do matrimônio e da família, evidenciada pela razão e confirmada pela revelação, mostra que a unidade e a indissolubilidade são elementos constitutivos da natureza do matrimônio com consequências jurídicas, sociais e eclesiais.

A consideração acerca da indissolubilidade é um ato de justiça aos cônjuges, aos filhos, à Igreja e à humanidade, tendo sua fundamentação bíblica e antropológica. João Paulo II convida a redescobrir a dimensão transcendente e intrínseca à verdade plena sobre o matrimônio e à família que significa uma relação matrimonial dos batizados com o mistério de Deus, definitivamente assumida pelo Cristo e elevada à condição de dignidade de sacramento. Este entrelaçamento entre dimensão natural e sobrenatural do matrimônio está na base das alocuções.

Deste modo, compreende-se que a instituição matrimonial é uma realidade pessoal indissolúvel e que goza do favor do direito, conforme expressão jurídica. Aqui está a dimensão moral da atividade dos agentes jurídicos nos Tribunais eclesiásticos e a necessidade de testemunhar a verdade sobre o matrimônio e não se deixar levar por outros interesses que não seja a verdade sobre o plano de Deus e a realização humana.

\section{BIBLIOGRAFIA}

\section{Fontes}

FRANCISCO. Cartas apostólicas em forma de motu proprio Mitis Iudex Dominus Iesus e Mitis et misericors Iesus sobre nulidade do matrimônio, Edições CNBB, Brasília, 2015. Misericórdia Vultus, São Paulo, Paulinas, 2015, n.20.

JOÃO PAULO II, Alocução ao Tribunal da Rota Romana: A função judicial da Igreja ao serviço da equidade e da caridade, in Insegnamenti di Giovanni Paolo II, vol. II, Libreria Editrice Vati- 
cana, 1979, p. 408-414, in L'Osservatore Romano, Ano X, n. 8 (482), 25 de fevereiro de 1979, p. 1-2.

, Alocução ao Tribunal da Rota Romana: A procura da verdade, suprema norma da justiça, in Acta Apostolica Sedis, vol. 72 (1980), p. 172-178, in L'Osservatore Romano, Edição Semanal em Português, Ano XI, n. 7 (533), 17 de fevereiro de 1980, p. 5 6.

, Alocução ao Tribunal da Rota Romana: Salvaguardar os valores do matrimônio para tutelar o grande bem da família, in Acta Apostolica Sedis, vol. 73 (1981), p. 228-234, in L'Osservatore Romano, Edição Semanal em Português, Ano XII, n. 6 (584), 8 de fevereiro de 1981, p. 1 e 3.

, Alocução ao Tribunal da Rota Romana: A vossa missão a serviço do amor consiste em reconhecer o pleno valor do matrimônio, in Acta Apostolica Sedis, vol. 74 (1982), p. 449-454, in L'Osservatore Romano, Edição Semanal em Português, Ano XIII, n. 6 (636), 7 de fevereiro de 1982, p. 3.

, Alocução ao Tribunal da Rota Romana: A maior função da Sagrada Rota é manifestada pela exemplar qualidade do trabaIho realizado, in Acta Apostolica Sedis, vol. 75 (1983), p. 554559, in L'Osservatore Romano, Edição Semanal em Português, Ano XIV, n. 10 (692), 6 de março de 1983, p. 9.

, Alocução ao Tribunal da Rota Romana: A fidelidade é o primeiro e mais importante dever do juiz, in Acta Apostolica Sedis, vol. 76 (1984), p. 643-649, in L'Osservatore Romano, Edição Semanal em Português, Ano XV, $\mathrm{n}^{\mathrm{o}} 6$ (740), 5 de fevereiro de 1984, p. 8.

, Alocução ao Tribunal da Rota Romana: $O$ vosso trabalho é judiciário, mas a vossa missão é fundamentalmente evangélica, eclesial e sacerdotal, in Acta Apostolica Sedis, vol. 78 (1986) p. 921-925, in L'Osservatore Romano, Edição Semanal em Português, Ano XVII, n. 8 (848), 23 de fevereiro de 1986, p. 1, 3. 
, Alocução ao Tribunal da Rota Romana: O Juiz não se deixe sugestionar por perícias baseadas em premissas antropológicas inaceitáveis, in Acta Apostolica Sedis, vol. 79 (1987), p. 14531459, in L'Osservatore Romano, Edição Semanal em Português, Ano XVIII, n. 7, 15 de fevereiro de 1987, p. 10-11.

, Alocução ao Tribunal da Rota Romana: $O$ respeito da visão cristã do matrimônio, in Acta Apostolica Sedis, vol. 80 (1988), p. 1178-1185, in L'Osservatore Romano, Edição Semanal em Português, Ano XIX, n. 7, 14 de fevereiro de 1988, p. 12.

, Alocução ao Tribunal da Rota Romana: A Lei garante o exercício do direito da defesa e regula-o para evitar abuso ou obstrucionismo, in Acta Apostolica Sedis, vol. 81 (1989), p. 922927, in L'Osservatore Romano, Edição Semanal em Português, Ano XX, n. 7 (1003), 12 de fevereiro de 1989, p. 5.

, Alocução ao Tribunal da Rota Romana: $O$ valor pastoral do direito na Igreja, in Acta Apostolica Sedis, vol. 82 (1990), p. 872-877, in L'Osservatore Romano, Edição Semanal em Português, Ano XXI, n. 4 (1053), 28 de janeiro de 1990, p. 3.

, Alocução ao Tribunal da Rota Romana: É preciso repropor integralmente a mensagem evangélica sobre o matrimônio, in Acta Apostolica Sedis, vol. 83 (1991), p. 947-953, in L'Osservatore Romano, Edição Semanal em Português, Ano XXII, n. 7 (1107), 28 de janeiro de 1991, p. 3.

, Alocução ao Tribunal da Rota Romana: Salvaguardar a imutabilidade da lei divina e a estabilidade da norma canonica, in Acta Apostolica Sedis, vol. 85 (1993), p. 140-143, in L'Osservatore Romano, Edição Semanal em Português, Ano XXIII, n. 5, 2 de fevereiro de 1992, p. 11.

, Alocução ao Tribunal da Rota Romana: A interpretação autêntica e verdadeira da lei, in Acta Apostolica Sedis, vol. 85 (1993), p. 1256-1260, in L'Osservatore Romano, Edição Semanal em Português, Ano XXIV, n. 7 (1110), 14 de fevereiro de 1993, p. 16. 
- Alocução ao Tribunal da Rota Romana: No Ano da Família emergem com clareza cada vez maior os riscos que a instituição familiar corre por causa de uma "compreensão" mal entendida, in Acta Apostolica Sedis, vol. 86 (1994), p. 947-952, in L'Osservatore Romano, Edição Semanal em Português, Ano 25, n. 6 (1261), 5 de fevereiro de 1994, p. 5.

, Alocução ao Tribunal da Rota Romana: A justiça e a consciência individual, in Acta Apostolica Sedis, vol. 87 (1995), p. 10131019, in S. GOMES (Org.), Alocuções dos Papas Paulo VI e João Paulo II ao Tribunal da Rota Romana, Lisboa: Universidade Católica, 2006, p. 233-239.

, Alocução ao Tribunal da Rota Romana: Ter em conta a peculiaridade de cada caso no processo de nulidade de matrimônio, in Acta Apostolica Sedis, vol. 88 (1996), p. 773-777, in L'Osservatore Romano, Edição Semanal em Português, Ano XXVII, n. 4 (1364), 27 de janeiro de 1996, p. 7.

, Alocução ao Tribunal da Rota Romana: Os reflexos jurídicos dos aspectos personalistas do matrimônio, in Acta Apostolica Sedis, vol. 89 (1997), p. 486-489, in L'Osservatore Romano, Edição Semanal em Português, Ano XXVIII, n. 6, 8 de fevereiro de 1997, p. 5.

, Alocução ao Tribunal da Rota Romana: A gravidade e o caráter insubstituível de princípios basilares revelam como é incongruente a pretensão de atribuir uma realidade "conjugal" à união entre pessoas do mesmo sexo, in Acta Apostolica Sedis, vol. 90 (1998), p. 781-785, in L'Osservatore Romano, Edição Semanal em Português, no 5 (1520), 30 de janeiro de 1999, p. 23.

, Alocução ao Tribunal da Rota Romana: O matrimônio sacramental ratificado e consumado jamais pode ser dissolvido, nem sequer pelo poder do Romano Pontífice, in Acta Apostolica Sedis, vol. 92 (2000), p. 350-355, in L'Osservatore Romano, Edição Semanal em Português, n. 5 (1572), 29 de janeiro de 2000, p. 4. 
, Alocução ao Tribunal da Rota Romana: A cultura individualista invasora tende a circunscrever e confinar o matrimônio e a família ao mundo privado, in Acta Apostolica Sedis, vol. 93 (2001), p. 358-365, in L'Osservatore Romano, Edição Semanal em Português, Ano XXXII, n. 6 (1626), 10 de fevereiro de 2001, p. 6-7.

, Alocução ao Tribunal da Rota Romana: $O$ bem da indissolubilidade é o bem próprio do matrimônio, in Acta Apostolica Sedis, vol. 94 (2002), p. 340-346, in L'Osservatore Romano, Edição Semanal em Português, Ano XXXIII, n. 5 (1677), 2 de fevereiro de 2002 , p. 7 e 10.

, Alocução ao Tribunal da Rota Romana: É preciso redescobrir a dimensão transcendente e intrínseca à verdade plena sobre o matrimônio e a família, in Acta Apostolica Sedis, vol. 95 (2003), p. 393-397. in L'Osservatore Romano, Edição Semanal em Português, Ano XXXIV, n. 6 (1730), 8 de fevereiro de 2003, p. 3.

, Alocução ao Tribunal da Rota Romana: $A$ instituição matrimonial é uma realidade pessoal indissolúvel elevada à dignidade de sacramento cristão, in Acta Apostolica Sedis, vol. 96 (2004), p. 348-352, in L'Osservatore Romano, Edição Semanal em Português, n. 6 (1782), 7 de fevereiro de 2004, p. 3.

, Alocução ao Tribunal da Rota Romana: A dimensão moral dos agentes jurídicos e o seu dever de se adaptar à verdade sobre o matrimônio, in Acta Apostolica Sedis, vol. 97 (2005), p. 164166, in L'Osservatore Romano, Edição Semanal em Português, Ano XXXVI, n. 6, 5 de fevereiro de 2005, p. 5.

\section{Autores}

A. BAGGOD, John Paul II's discrete eye for science, in Angelicum 82 (2005), Fasc. 2, p. 355-372.

D. GERALDO, A teologia do direito matrimonial nas alocuções de Bento XVI ao tribunal da rota romana, in Horizonte, v. 13, n. 38 (abr./jun 2015), p. 1103-1121. 
D. GERALDO - V. J. RIBEIRO, A reforma no processo de nulidade matrimonial e sua gênese no Sínodo dos Bispos, in Revista Eclesiástica Brasileira (REB), vol. 302 (2016), p. 356-374.

E. KACZYNSKI, Legge naturale e diritti umani in Karol Wojtyla, in Angelicum 82 (2005), Fasc. 2, 287-310.

P. AMENTA, Misericodioso e giusto, Tau Editrice, Todi, 2017.

R. K. WILK, La persona umana nella filosofia di Karol Wojtyla, in Angelicum, vol. 82 (2005), Fasc. 2, p. 373-388.

Z. GROCHOLEWSKI, La filosofia del diritto di Giovanni Paolo II, Editrice Falma Edium, Roma, 2002. 